\title{
The DNA methylation of FOXO3 and TP53 as a blood biomarker of late-onset asthma
}

\author{
Lin Yuan 1,2,3, Leyuan Wang ${ }^{2}$, Xizi Du², Ling Qin 1,3, Ming Yang ${ }^{4}$, Kai Zhou ${ }^{2}$, Mengping Wu ${ }^{2}$, Yu Yang ${ }^{2}$, \\ Zhiyuan Zheng ${ }^{1,3}$, Yang Xiang ${ }^{2}$, Xiangping Qu², Huijun Liu², Xiaoqun Qin² and Chi Liu ${ }^{1,2,5^{*}}$ (D)
}

\begin{abstract}
Background: Late-onset asthma ( $L O A)$ is beginning to account for an increasing proportion of asthma patients, which is often underdiagnosed in the elderly. Studies on the possible relations between aging-related genes and LOA contribute to the diagnosis and treatment of LOA. Forkhead Box O3 (FOXO3) and TP53 are two classic aging-related genes. DNA methylation varies greatly with age which may play an important role in the pathogenesis of LOA. We supposed that the differentially methylated sites of FOXO3 and TP53 associated with clinical phenotypes of LOA may be useful biomarkers for the early screening of LOA.
\end{abstract}

Methods: The mRNA expression and DNA methylation of FOXO3 and TP53 in peripheral blood of 43 LOA patients (15 mild LOA, 15 moderate LOA and 13 severe LOA) and 60 healthy controls (HCs) were determined. The association of methylated sites with age was assessed by Cox regression to control the potential confounders. Then, the correlation between differentially methylated sites (DMSs; $p$-value $<0.05$ ) and clinical lung function in LOA patients was evaluated. Next, candidate DMSs combining with age were evaluated to predict LOA by receiver operating characteristic (ROC) analysis and principal components analysis (PCA). Finally, HDM-stressed asthma model was constructed, and DNA methylation inhibitor 5-Aza-2'-deoxycytidine (5-AZA) were used to determine the regulation of DNA methylation on the expression of $\mathrm{FOXO} 3$ and TP53.

Results: Compared with HCs, the mRNA expression and DNA methylation of FOXO3 and TP53 vary significantly in LOA patients. Besides, 8 DMSs from LOA patients were identified. Two of the DMSs, chr6:108882977 (FOXO3) and chr17:7591672 (TP53), were associated with the severity of LOA. The combination of the two DMSs and age could predict LOA with high accuracy (AUC values $=0.924$ ). In HDM-stressed asthma model, DNA demethylation increased the expression of $\mathrm{FOXO} 3$ and $\mathrm{P} 53$.

Conclusions: The mRNA expression of FOXO3 and TP53 varies significantly in peripheral blood of LOA patients, which may be due to the regulation of DNA methylation. FOXO3 and TP53 methylation is a suitable blood biomarker to predict LOA, which may be useful targets for the risk diagnosis and clinical management of LOA.

Keywords: DNA methylation, Aging, Late-onset asthma, FOXO3, TP53

\footnotetext{
*Correspondence: liu.chi@csu.edu.cn

${ }^{2}$ Department of Physiology, Xiangya School of Basic Medicine Science,

Central South University, Changsha 410078, Hunan, China

Full list of author information is available at the end of the article
}

\begin{abstract}
Introduction
Asthma symptoms can occur at any time in life though many patients may develop asthma during childhood. The endotype of asthma has a diversity of distinguished clinical phenotypes which is critical for the diagnosis and treatment of different types of asthma. LOA is defined as a kind of asthma with onset of symptoms in adult life in a patient with no pre-existing, persistent respiratory
\end{abstract} the original author(s) and the source, provide a link to the Creative Commons licence, and indicate if changes were made. The images or other third party material in this article are included in the article's Creative Commons licence, unless indicated otherwise in a credit line to the material. If material is not included in the article's Creative Commons licence and your intended use is not permitted by statutory regulation or exceeds the permitted use, you will need to obtain permission directly from the copyright holder. To view a copy of this licence, visit http://creativecommons.org/licenses/by/4.0/. The Creative Commons Public Domain Dedication waiver (http://creativeco mmons.org/publicdomain/zero/1.0/) applies to the data made available in this article, unless otherwise stated in a credit line to the data. 
symptoms [1, 2]. With the worldwide population trend toward enhanced longevity, clinical concerns about LOA are developing which is frequently underdiagnosed in elder age groups. However, the underlying pathogenesis of LOA is still obscure, which have not identified early biomarkers until now. Lung aging has been recognized as an important risk factor and a key pathological basis of LOA [3]. Along with the growth of age, structural and functional changes occur in the lungs of the elderly, leading to an increased risk of pulmonary diseases, more severe pulmonary pathological phenotype and poor clinical treatment $[4,5]$. Also, in aging-related chronic obstructive pulmonary disease (COPD) and LOA, agingrelated molecular events (such as telomere shortening, epigenetic alterations, ROS accumulation and immunosenescence) are more pronounced [6-8]. The role of lung aging in the pathogenesis of COPD has been extensively studied and confirmed, however, the mechanisms underlying the relations between aging and LOA are still unclear.

FOXO3 and TP53 are two classic genes that regulate aging and longevity $[9,10]$. FOXO3 is a member of FOXO transcription factors and belongs to Forkhead family. It is an important transcriptional factor for DNA repair and production of anti-oxidants [11], which is closely related to human longevity $[12,13]$. FOXO3 deficiency leads to airspace enlargement, enhanced inflammation and increased sensitivity to COPD after cigarette smoking [14]. Similarly, TP53 has been shown to be involved in the progression of COPD by mediating the senescence of multiple lung cells [15-17]. Although previous studies suggested that the gene polymorphisms in FOXO3 and TP53 are associated with asthma susceptibility [18-20], little is known about the involvement of FOXO3 and TP53 in the pathogenesis of LOA.

Lungs exchange gas with the outside world, which are highly susceptible to external environmental conditions [21]. Therefore, epigenetic modifications have been shown to play an important role in the pathogenesis of asthma. DNA methylation is the most in-depth epigenetic marker in aging-related diseases [22, 23]. It is an important mechanism in the regulation of gene expression which is also closely related to clinical phenotypic changes [24, 25]. As proven, it could be used for risk prediction and early diagnosis in many different diseases [26-28]. Moreover, it is intriguing that aberrant DNA methylation in cancer should be associated with the expression of FOXO3 and TP53, respectively [29, 30]. In the study, we firstly investigated the expression and DNA methylation of FOXO3 and TP53 in peripheral blood of LOA patients. Then, we analyzed the correlation between DMSs and lung function in LOA patients. Finally, we evaluated the feasibility of methylation of FOXO3 and
TP53 as blood biomarkers for LOA and determined the regulation of DNA methylation on the expression of FOXO3 and TP53.

\section{Materials and methods}

\section{Selection of patients with LOA, clinical criteria}

Criteria for the diagnosis of asthma were recommended by the 2019 Global Strategy for Asthma Management and Prevention [31]. Briefly, it is defined by the history of respiratory symptoms such as wheeze, shortness of breath, chest tightness and cough that vary over time and in intensity, together with variable expiratory airflow limitation. According to asthma severity, asthma is divided into mild asthma, moderate asthma, and severe asthma. Asthma severity is assessed retrospectively from the level of treatment required to control symptoms and exacerbations. Specific clinical criteria also refer to 2019 Global Strategy for Asthma Management and Prevention [31].

LOA is one of the main endotypes of asthma that have been identified [32]. It refers to people develop asthma symptoms for the first time in adulthood [8], specifically defined as: "asthma with onset of symptoms in adult life in a patient with no pre-existing, persistent respiratory symptoms," but the definition of age has not been clarified. The cut-off for LOA was set at the age of 13,40 or 60 years in different researches [1, 2, 33, 34].

\section{Recruitment of participants and data collection}

60 healthy controls (HCs) and 43 previously confirmed LOA patients ( $>20$ years of age) were selected from the Respiratory Department and the Medical Examination Center of Xiangya Hospital in China from October 2018 to January 2019. After Written informed consent was obtained from each patient, questionnaire information (general condition, smoking history and other respiratory diseases), pulmonary function testing, peripheral blood and induced sputum samples were collected. Lung function test included the spirometric values of $\mathrm{FEV}_{1}, \mathrm{FEV}_{1} \%$ predicted, FVC, the ratio of $\mathrm{FEV}_{1}$ to the FVC, PEF, $\mathrm{FEF}_{75}, \mathrm{FEF}_{50}$ and $\mathrm{FEF}_{25}$. The study was approved by No. 20180308 of the Xiangya Hospital Ethics Review Committee and participants provided written consents to participate in this study.

\section{Sample collection}

Peripheral blood and induced sputum samples were collected from the enrolled $60 \mathrm{HCs}$ and 43 LOA patients, respectively. Peripheral blood was collected into $5 \mathrm{ml}$ EDTA anticoagulation tubes and then transferred to a centrifuge tube. After adding 2 volumes of erythrocyte lysate and lysing for $5 \mathrm{~min}$, peripheral blood cells were pelleted by centrifugation. 
For sputum induction, each volunteer inhaled a $4.5 \%$ saline atomized solution three times for $5 \mathrm{~min}$ each time and coughed sputum into a separate cup. Then, fourparts $0.1 \%$ dithiothreitol was added to one-part sputum and mixed for $15 \mathrm{~min}$ before adding four-parts phosphate-buffered saline. Finally, sputum cells were pelleted by centrifugation and used for RNA extraction after filtering [35].

\section{RNA extraction, RT-PCR and quantitative RT-PCR}

Total mRNA was purified from peripheral blood and induced sputum cells using Trizol (Invitrogen) and quantified by an ultraviolet spectrophotometer (Thermo Fisher Scientific, USA) [36]. $1 \mu \mathrm{g}$ RNA was reversely transcribed into cDNA using Reverse Transcriptase Kit (Qiagen, Netherlands) in accordance to the manufacturer's instructions [37]. Then, quantitative RT-PCR was performed using SYBR ${ }^{\circledR}$ Premix Ex Taq $^{\mathrm{TM}}$ II system (TaKaRa, Japan) with the CFX96 Touch $^{\mathrm{TM}}$ Real-Time PCR Detection System (Bio-Rad, USA). The PCR conditions were as follows: $95{ }^{\circ} \mathrm{C}$ for $30 \mathrm{~s}, 40$ cycles of $95{ }^{\circ} \mathrm{C}$ for $15 \mathrm{~s}$, and $60{ }^{\circ} \mathrm{C}$ for $30 \mathrm{~s}$. Resulting mRNA levels were normalized to $\beta$-actin and expressed as a fold change relative to control samples. The sequences of the primers used are as follows: FOXO3 (forward, CGG ACA AAC GGC TCA CTC T; reverse, GGA CCC GCA TGA ATC GAC TAT), TP53 (forward, AAG TCT GTG ACT TGC ACG TAC TCC; reverse, GTC ATG TGC TGT GAC TGC TTG TAG) and $\beta$-actin (forward, TTC CAG CCT TCC TTC CTG GG; reverse, TTG CGC TCA GGA GGA GCA AT).

\section{DNA extraction, bisulfite treatment, methylation array methods}

Genomic DNA was extracted from peripheral blood with the TIANamp Genomic DNA kit (Tiangen Biotech, China) [38]. DNA quality control, bisulfite processing, methylation library construction and high-throughput sequencing were carried out at Genesky Biotechnologies Inc. Shanghai [39]. CpG islands were selected which located between $2 \mathrm{~K}$ upstream of the gene transcription start site and $1 \mathrm{~K}$ downstream of the first exon, to measure methylation levels. Specific selection methods of CpG islands and detection methods of methylation level are performed according to previous literature [40]. $3 \mathrm{CpG}$ islands of FOXO3 and $2 \mathrm{CpG}$ islands of TP53 were selected. Based on these CpG islands, multiple CpG regions (Targets) from CpG islands in FOXO3 and TP53 were sequenced. The details of the $\mathrm{CpG}$ regions are listed in Additional file 1: Table S1. Finally, 171 CpG sites from FOXO3 and 48 CpG sites from TP53 were detected in the methylation assay and the details of the CpG sites can be found in Additional file 2: Table S2. We only retained the raw data with a sequencing quality value $\mathrm{Q}>40$ (Base sequencing error rate $<0.1 \%$ ) and reported the percent methylation of every CpG site.

\section{Animals}

This animal study was carried out with the approval No. 2020sydw0178 of Xiangya Animal Protection and Utilization Committee of Central South University. All methods are implemented in accordance with relevant clauses. The mice were placed under the condition of an air-filtered temperature control unit, where the light and dark cycled alternately for $12 \mathrm{~h}$, with sufficient food and water supply. The HDM-induced asthma model was constructed according to previous publications [41]. In the last two weeks, 5-AZA (Sigma-Aldrich) $(1 \mathrm{mg} / \mathrm{kg}$ body weight) were injected intraperitoneally $1 \mathrm{~h}$ before HDM challenge to inhibit DNA methylation [42]. All mice were killed $48 \mathrm{~h}$ after the last challenge.

\section{Immunohistochemical staining}

Lungs were inflated, fixed in $4 \%$ paraformaldehyde, and embedded in paraffin blocks and cut into $5 \mu \mathrm{m}$ sections. Immunohistochemistry staining was performed with the following antibodies: p53 (Ab31333, Abcam), FOXO3 (Ab12162, Abcam). For microscopy, we employed Zeiss Axio Scope.A1 or Zeiss Discovery.V8 Stereo microscopes (Carl Zeiss MicroImaging GmbH, Germany) integrated with an Axio-Cam ICc3 camera (Spectra Service, Ontario, NY). Images were obtained by AxioVision Rel. 4.7 software from Zeiss.

\section{Statistical analysis}

Statistical analyses were conducted using SPSS version 22.0 (IBM Corporation, Armonk, NY, USA). The characteristic data of recruited LOA patients and HCs were presented as Mean $\pm \mathrm{SD}$ and analyzed with Chi-squared test or Mann-Whitney U test. The mRNA expression and the methylation array of FOXO3 and TP53 were analyzed by One-way ANOVA followed by Dunnett's post hoc test. The method of Benjamin Hochberg was used to control the false discovery rate (FDR). Logistic regression analysis was performed on selected differentially expressed CpG sites, with potential risk factor of age, gender and smoking history [43]. Pearson's correlation or Spearman's correlation was used to assess the association between the percentage of methylation of differentially expressed $\mathrm{CpG}$ sites and the continuous variables such as $\mathrm{FEV}_{1}$, $\mathrm{FEV}_{1} \%, \mathrm{FEV}_{1} / \mathrm{FVC}$. Receiver operating characteristic (ROC) curves were obtained to elucidate the accuracy of differentially expressed CpG sites in predicting LOA. Age and the methylation percentage of candidate $\mathrm{CpG}$ sites were used in principal components analysis (PCA) to identify LOA. A two-tailed p-value $<0.05$ was considered statistically significant. 


\section{Results}

Differential expression of FOXO3 and TP53 in peripheral blood and induced sputum of LOA patients and HCs To detect the expression of FOXO3 and TP53 in LOA patients, we recruited $60 \mathrm{HCs}$ and $43 \mathrm{LOA}$ patients (including 15 mild LOA, 15 moderate LOA, and 13 severe LOA). The percentage of eosinophils and neutrophils in LOA patients was significantly higher than that of HCs. There was no statistical difference in age between these groups (Table 1). By comparing the mRNA expression in the peripheral blood of $\mathrm{HC}<60$ years old and $\geq 60$ years old, it was found that the expression of FOXO3 and TP53 was related to age (Fig. 1a, b). The expression change of TP53 and FOXO3 in peripheral blood and induced sputum was consistent. The mRNA expression of FOXO3 increased in mild LOA patients and decreased in severe LOA patients (Fig. 1c, e). While the expression of TP53 decreased both in mild LOA patients and severe LOA patients (Fig. 1d, f). Furthermore, we also performed correlation analyses between the FOXO3 and TP53 mRNA levels and lung function indicators in LOA patients. The result showed that their mRNA expression had varying degrees of correlation with lung function (Additional file 3: Table S3).

\section{DNA methylation of FOXO3 and TP53 in peripheral blood of patients with LOA and HCs}

Since DNA methylation of CpG sites in the promoter (including the TSS) and first exon regions is closely related to gene transcription [44], we assessed CpG islands located between $2 \mathrm{~K}$ upstream of the gene transcription start site and $1 \mathrm{~K}$ downstream of the first exon. $3 \mathrm{CpG}$ islands of FOXO3 including $171 \mathrm{CpG}$ sites (Fig. 2a) and $2 \mathrm{CpG}$ islands of TP53 including $48 \mathrm{CpG}$ sites were selected (Fig. 3a). The details of the $\mathrm{CpG}$ islands was listed in Table 2. Then, the DNA methylation level of these CpG sites in FOXO3 and TP53 was evaluated. Continuous decreased methylation pattern of $\mathrm{CpG}$ sites in specific regions of FOXO3-2 was detected in mild, moderate and severe LOA patients (Fig. 2b-d), while the dominant methylated sites of TP53 was relatively scattered (Fig. 3b, c). The volcano plot also showed that the methylation levels of these CpG sites in FOXO3 (Fig. 2e) and TP53 (Fig. 3d). At $p$-value $<0.05$ and the absolute value of meth diff $>$ $0.1 \%, 15$ methylated sites in FOXO3 and 2 methylated sites in TP53 were associated with LOA.

To assess the effect of DMSs more accurately on LOA, logistic regression with age, gender or smoking history was used to determine other possible potential risk factors. The results demonstrated that the age of participants in the study was related to LOA but not to gender and smoking history (data not shown). Hence, a logistic regression analysis with potential risk factors adjustment was further performed. Finally, 7 DMSs in FOXO3 and 1 DMS in TP53 were statistically significant, and the absolute value of methylation difference between the 8 sites ranged from $0.31 \%$ to $11.70 \%$ (Table 3).

Table 1 Demographic characteristics of the HCs and LOA patients

\begin{tabular}{|c|c|c|c|c|}
\hline & $\mathrm{HCs}$ & Mild LOA & Moderate LOA & Severe LOA \\
\hline Number of subjects & 60 & 15 & 15 & 13 \\
\hline Age & $53.96 \pm 6.89$ & $57.60 \pm 13.11$ & $55.60 \pm 8.80$ & $50.14 \pm 10.25$ \\
\hline Female (\%) & 83.33 & 73.33 & 80.00 & $46.15^{*}$ \\
\hline Smoking history (\%) & 13.33 & 13.33 & 6.67 & 15.38 \\
\hline $\mathrm{FEV}_{1}$ & $2.87 \pm 0.21$ & $2.22 \pm 0.60^{*}$ & $1.78 \pm 0.38^{*}$ & $1.14 \pm 0.47^{*}$ \\
\hline $\mathrm{FEV}_{1} \%$ predicted & $0.94 \pm 0.27$ & $0.89 \pm 0.57^{*}$ & $0.70 \pm 0.06^{*}$ & $0.41 \pm 0.14^{*}$ \\
\hline FVC & $4.07 \pm 0.61$ & $3.11 \pm 0.80^{*}$ & $2.95 \pm 0.85^{*}$ & $2.39 \pm 0.78^{*}$ \\
\hline $\mathrm{FEV}_{1} / \mathrm{FVC}$ & $0.84 \pm 0.05$ & $0.71 \pm 0.07^{*}$ & $0.62 \pm 0.10^{*}$ & $0.48 \pm 0.12^{*}$ \\
\hline PEF & $8.37 \pm 0.94$ & $6.22 \pm 1.85^{*}$ & $4.26 \pm 0.85^{*}$ & $2.83 \pm 1.16^{*}$ \\
\hline $\mathrm{FEF}_{75}$ & $0.89 \pm 0.37$ & $0.72 \pm 0.20^{*}$ & $0.45 \pm 0.14^{*}$ & $0.21 \pm 0.10^{*}$ \\
\hline $\mathrm{FEF}_{50}$ & $0.84 \pm 0.31$ & $0.49 \pm 0.15^{*}$ & $0.33 \pm 0.13^{*}$ & $0.13 \pm 0.06^{*}$ \\
\hline $\mathrm{FEF}_{25}$ & $0.74 \pm 0.25$ & $0.37 \pm 0.12^{*}$ & $0.23 \pm 0.07^{*}$ & $0.15 \pm 0.07^{*}$ \\
\hline Blood eosinophilia (\%) & $1.27 \pm 3.29$ & $4.03 \pm 3.91^{*}$ & $8.22 \pm 6.48^{*}$ & $7.53 \pm 6.60^{*}$ \\
\hline Blood neutrophils (\%) & $40.76 \pm 17.47$ & $58.82 \pm 15.91^{*}$ & $60.17 \pm 12.29^{*}$ & $71.39 \pm 10.44^{*}$ \\
\hline Sputum eosinophils (\%) & $1.11 \pm 0.53$ & $3.58 \pm 1.80^{*}$ & $9.72 \pm 7.24^{*}$ & $11.56 \pm 9.35^{*}$ \\
\hline Sputum neutrophils (\%) & $25.05 \pm 3.26$ & $31.98 \pm 7.35^{*}$ & $33.37 \pm 6.31^{*}$ & $42.02 \pm 10.29^{*}$ \\
\hline
\end{tabular}

Data are presented as Mean \pm SD. ${ }^{*} p<0.05$, HCs VS LOA patients (Chi-squared test for Female and Smoking history; Unpaired t test for other demographic Characteristics) 


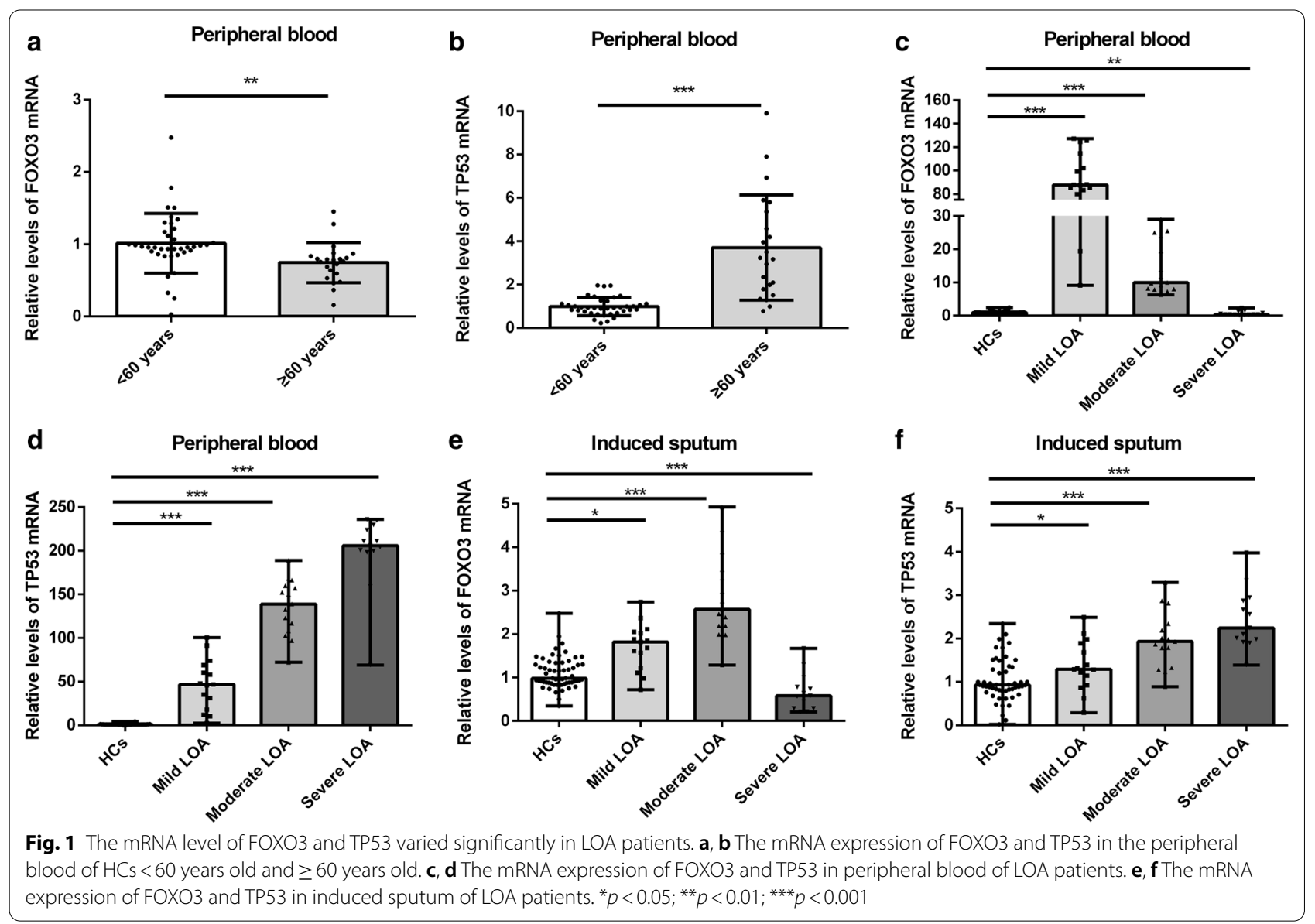

\section{Potential correlation between DMSs and lung function in LOA patients}

To elucidate that DNA methylation of FOXO3 and TP53 is associated with the severity or exacerbation of LOA, we further analyzed the correlation between the 8 DMSs and lung function indicators of LOA patients, as pulmonary function is an important evaluation basis for the classification and control of asthma severity. Correlation analyses revealed that 2 DMSs were related to changes in lung function indicators (Additional file 4: Table S4). In particular, elevated methylation level of chr6:108882977 (FOXO3) was associated with reduced $\mathrm{FEV}_{1} \%$ and PEF (Fig. 4a, b); methylation level of chr17:7591672 (TP53) was positively related to the changes of $\mathrm{FEV}_{1}, \mathrm{FVC}$, PEF and $\mathrm{FEF}_{25}$ (Fig. 5ad). Moreover, the methylated site chr6:108882982 (FOXO3) appeared to be associated with decreased lung function, though there was no significant statistical difference (Additional file 4: Table S4).

\section{DNA methylation level of chr6:108882977 and chr17:591672 as biomarker of LOA}

Since the two DMSs (chr6:108882977 and chr17:7591672) were related to age and lung function indicators (Fig. 6a, b), we further analyzed the accuracy of these two DMSs to predict LOA. The methylation levels of chr6:108882977 (FOXO3) decreased in mild and moderate LOA patients (Fig. 6c). While the level of chr17:7591672 (TP53) decreased both in mild LOA patients and severe LOA patients (Fig. 6d). Our previous results demonstrated that age was associated with LOA, so ROC curve analysis was performed after age integration with methylation of chr6:108882977 or chr17:7591672, respectively. ROC curve analysis showed that the chr6:108882977 or chr17:7591672 had high AUC values of 0.878 and 0.898 , respectively (Table 3 and Fig. 6e, f). Further, the AUC value increased to 0.924 (Fig. 6g) when ROC analysis was performed in combination with the two DMSs and 


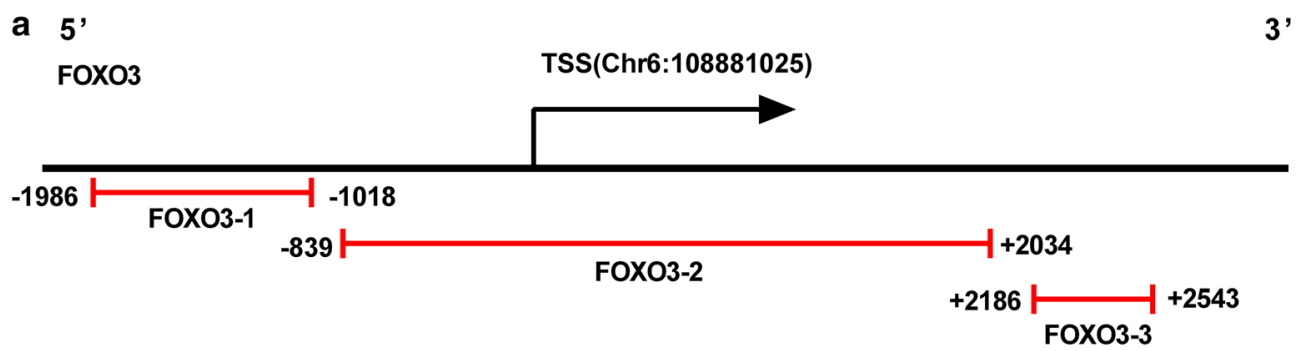

b

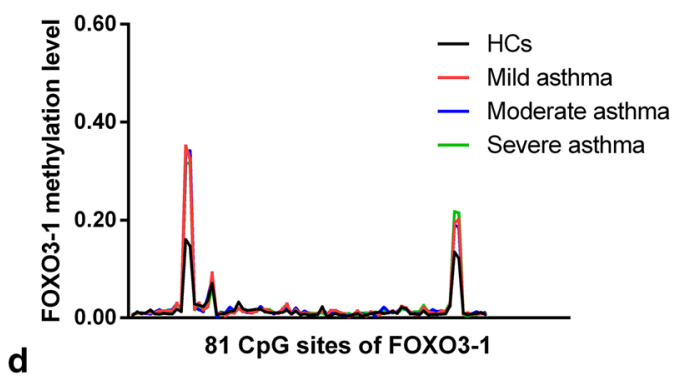

d

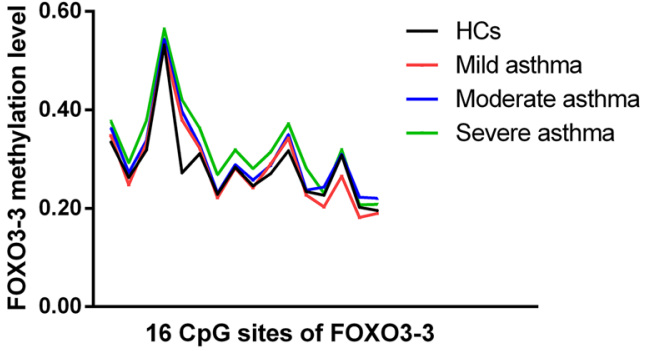

C
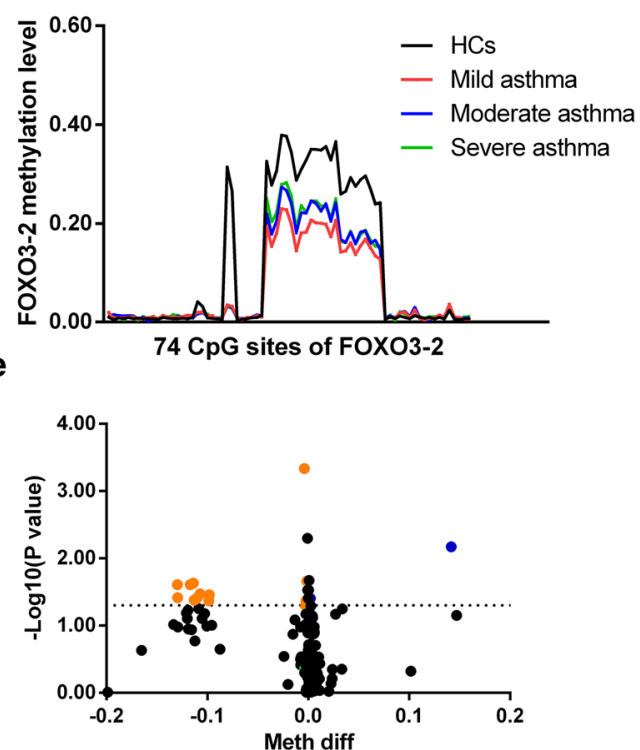

Fig. 2 Variable DNA methylation of FOXO3 gene's CpG islands in LOA. a Schematic representation of CpG islands sequenced FOXO3. CpG islands are indicated in Red lines. The Range of each islands is indicated by its relative distance (in bp) to TSS; $\mathbf{b}-\mathbf{d}$ Mean DNA methylation level of the three CpG islands (FOXO3-1, FOXO3-2, FOXO3-3) are presented from LOA patients and HCs, respectively; e Volcano plot of DMSs in FOXO3 between LOA patients and HCs. The up-regulated sites were presented as blue dots and down-regulated sites were presented as orange dots

ages. The PCA plot consisting of the two DMSs and age also demonstrated that the methylation levels of chr6:108882977 (FOXO3) and chr17:7591672 (TP53) could distinguish LOA patients from $\mathrm{HCs}$ effectively (Fig. 6h). For the other 6 DMSs, we also performed ROC curve analysis, and the results were shown in Table 3 and Additional file 5: Figure S1.

\section{DNA demethylation further increased the expression of FOXO3 and P53 in HDM-stressed asthma model}

To determine the regulation of DNA methylation on the expression of FOXO3 and TP53, 5-AZA were used to block DNA methylation in HDM-stressed asthma model. The expression of FOXO3 and P53 in lung tissue, BALF and peripheral blood were increased after HDM stress. And the administration of 5-AZA further increased the expression of FOXO3 and P53 compared to HDM-stressed group (Fig. 7a-f). These results indicated that DNA demethylation was involved in regulating the expression of FOXO3 and TP53 in asthma patients.

\section{Discussion}

Epidemiological studies in recent years have shown that LOA is increasing because of the aging of the population [45]. Moreover, LOA patients are at a higher risk for morbidity and mortality than younger asthma patients [46]. Interestingly, accumulating studies have suggested that the high incidence of LOA is closely related to lung aging [8]. As DNA methylation is the most intensively studied epigenetic mark in aging related studies which represents a very stable sign, aging-related DNA methylation may be used as a valuable biomarker for LOA screening $[47,48]$. Here, our study demonstrated that the expression and methylation of two classic aging-related genes (FOXO3 and TP53) vary significantly in LOA patients. Besides, 8 DMSs were identified from LOA patients. Two of the DMSs were associated with the severity of LOA. The combination of the two DMSs and age could predict LOA with high accuracy. Moreover, the regulation of DNA methylation on the expression of FOXO3 and TP53 was determined through in vivo experiments. 


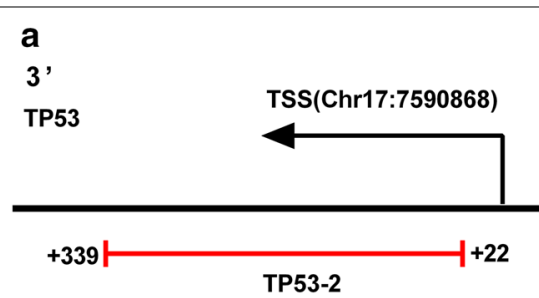

b

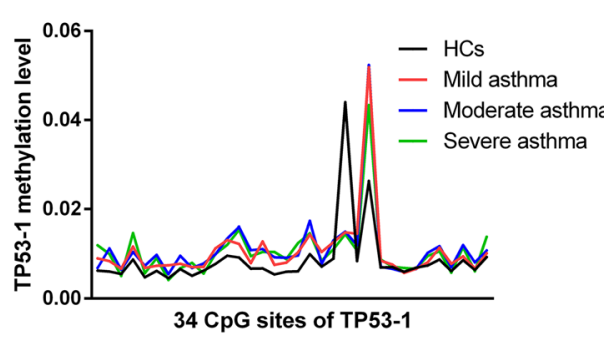

d

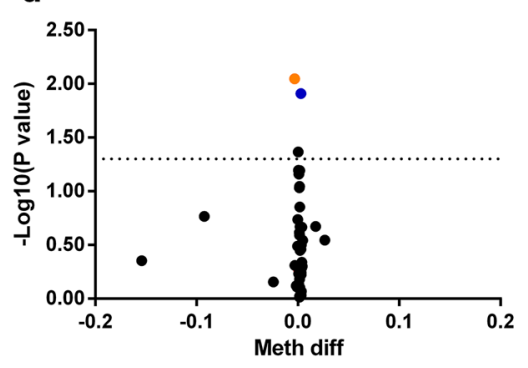

5

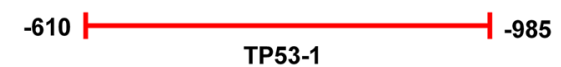

C

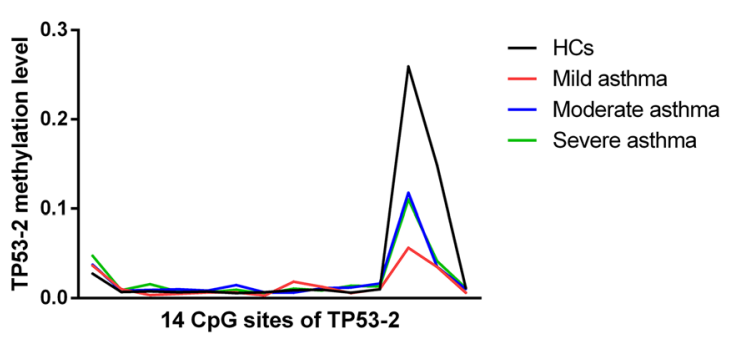

Fig. 3 Variable DNA methylation of TP53 gene's CpG islands in LOA. a Schematic representation of CpG islands sequenced TP53; b, c Mean DNA methylation level of the two CpG islands (TP53-1, TP53-2) from LOA patients and HCs, respectively; d Volcano plot of DMSs in TP53 between LOA patients and $\mathrm{HCS}$

Table 2 Details of the CpG islands of FOXO3 and TP53

\begin{tabular}{|c|c|c|c|c|c|c|c|c|}
\hline CpG islands & Chr & mRNA strand & TSS & Start & End & Length & Distance & CpG sites \\
\hline FOXO3-1 & 6 & + & 108881025 & 108879039 & 108880007 & 968 & -1018 & 81 \\
\hline $\mathrm{FOXO3-2}$ & 6 & + & 108881025 & 108880186 & 108883059 & 2873 & -839 & 74 \\
\hline FOXO3-3 & 6 & + & 108881025 & 108883211 & 108883568 & 357 & 2186 & 16 \\
\hline TP53-1 & 17 & - & 7590868 & 7591853 & 7591478 & 375 & -610 & 34 \\
\hline TP53-2 & 17 & - & 7590868 & 7590846 & 7590529 & 317 & 22 & 14 \\
\hline
\end{tabular}

TSS: The mRNA transcription initiation site; Start: The starting position of the CpG island on the reference genome; End: The end position of the CpG island on the reference genome; Length: the CpG island length; Distance: The distance from the CpG island to the TSS

FOXO3 is an evolutionarily conserved transcription factor involved in a wide spectrum of biological processes, including aging, apoptosis, and tumor [49]. Previous studies have demonstrated single nucleotide polymorphisms in FOXO3 in peripheral blood of asthma patients $[19,50]$, and the expression of FOXO3 decreased significantly in the lungs of smokers or COPD patients [14]. It has also found a significant reduction of FOXO3 expression in the bronchial epithelial cells of asthmatic patients [51]. Our results showed that smoking history had nothing to do with LOA. Because the proportion of smokers in our samples was relatively small, we speculated that the altered methylation levels and expression of FOXO3 and TP53 may be caused by other factors like air pollution and occupational exposures $[52,53]$. The results further demonstrated that the mRNA expression of FOXO3 was elevated in patients with mild to moderate LOA, whereas decreased in patients with severe 
Table 3 Differences in methylation sites of FOXO3 and TP53 in LOA patients

\begin{tabular}{|c|c|c|c|c|c|c|}
\hline CpG Site & CpG island & $\begin{array}{l}\text { Mean difference } \\
\text { methylation }\end{array}$ & $\begin{array}{l}\text { FDR adjusted } \\
p \text {-value }\end{array}$ & $p$-value (logit) & AUC & $p$-value (AUC) \\
\hline chr6:108879441 & FOXO3-1 & $-0.39 \%$ & $<0.001^{*}$ & $0.013^{*}$ & 0.925 & $<0.001^{*}$ \\
\hline chr6:108879922 & FOXO3-1 & $-0.22 \%$ & $0.043^{*}$ & $0.026^{*}$ & 0.895 & $<0.001^{*}$ \\
\hline chr6:108880271 & FOXO3-2 & $-0.08 \%$ & $0.005^{*}$ & $0.048^{*}$ & 0.887 & $<0.001^{*}$ \\
\hline chr6:108882982 & $\mathrm{FOXO} 3-2$ & $-11.70 \%$ & $0.025^{*}$ & $0.041^{*}$ & 0.887 & $<0.001^{*}$ \\
\hline chr6:108882977 & $\mathrm{FOXO} 3-2$ & $-11.39 \%$ & $0.023^{*}$ & $0.035^{*}$ & 0.878 & $<0.001^{*}$ \\
\hline chr6:108882964 & $\mathrm{FOXO} 3-2$ & $-11.00 \%$ & $0.038^{*}$ & $0.046^{*}$ & 0.880 & $<0.001^{*}$ \\
\hline chr6:108882825 & $\mathrm{FOXO} 3-2$ & $-10.72 \%$ & $0.034^{*}$ & $0.049^{*}$ & 0.885 & $<0.001^{*}$ \\
\hline chr17:7591672 & TP53-1 & $-0.31 \%$ & $0.009^{*}$ & $0.043^{*}$ & 0.898 & $<0.001^{*}$ \\
\hline
\end{tabular}

Differential methylation analysis was conducted between LOA patients and HCs in peripheral blood. The method of Benjamin Hochberg was used to control the false discovery rate $(\mathrm{FDR}),{ }^{*} p<0.05$; Age factor was adjusted in the logistic regression analysis
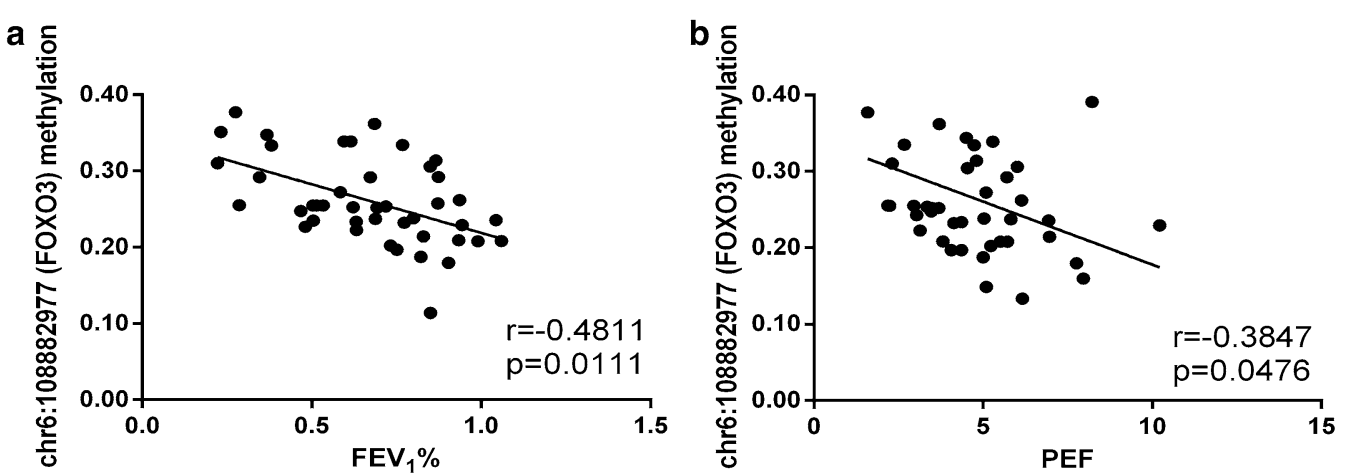

Fig. 4 Correlation analysis between chr6:108882977 (FOXO3) and clinical lung function. a, b The methylation level of chr6:108882977 (FOXO3) was negatively correlated with $\mathrm{FEV}_{1} \%$ and $\mathrm{PEF}$

LOA. FOXO3 had a pivotal role in inhibiting apoptosis, resisting oxidation, extending cell lifespan and preventing against aging-related diseases [54]. The increased FOXO3 expression may be due to the trigger of protective selfdefense mechanisms in mild and moderate LOA patients. TP53 is one of the key genes involved in aging and plays a key role in aging by inhibiting the cell cycle $[55,56]$. Studies have verified that genetic polymorphisms in TP53 are associated with asthma susceptibility [18]. It is also shown that prolonged exposure to cigarette smoke extract increases $\mathrm{p} 53$ protein expression in the lungs of mice which is consistent with our results [57]. Interestingly, we noticed that the expression changes of FOXO3 and TP53 in the peripheral blood of LOA patients reached ten times or more, which was similar to the expression changes in HDM-stressed mice model. After HDM stress, the expression change of FOXO3 and P53 in peripheral blood was much larger than that in lung tissue and BALF. As DNA methylation is tissue specific [58], there may be unpredictable differences in methylation level between peripheral blood sample and lung tissue sample. Moreover, both FOXO3 and TP53 have been verified to regulate their own expression via different positive feedback loops [59-62]. The regulation of the expression of FOXO3 and TP53 by DNA demethylation may initiate these positive feedback and then amplify expression changes. However, it is still unclear whether the positive feedback loop is based on DNA methylation, transcription or translation, which still requires further research.

In addition, our results also revealed that there were 8 CpG sites associated with LOA in the CpG islands of FOXO3 and TP53. Among them, chr6:108882977 (FOXO3) and chr17:7591672 (TP53) were closely related to the severity of LOA. On this basis, we further explored the possible regulation of gene expression by the two DMSs and the feasibility of the two DMSs as LOA biomarkers. Hypermethylation modifications usually result in decreased target gene expression [63, 64]. Consistent with this, methylation levels of chr6:108882977 (FOXO3) showed a negative regulation on FOXO3 expression. However, it was worth noting that FOXO3 mRNA expression was down-regulated in severe LOA, while there was no significant difference in DNA methylation 
a

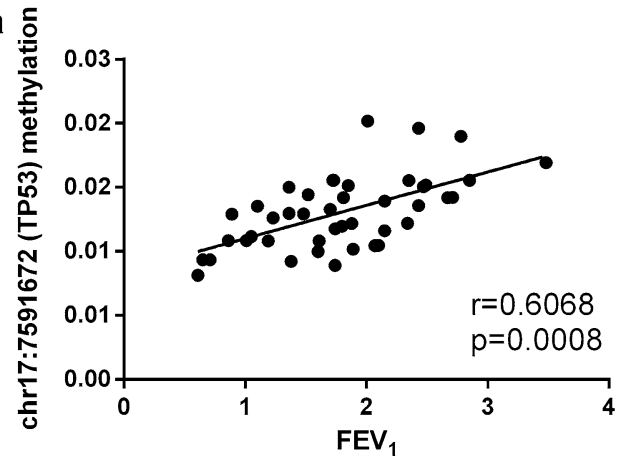

C

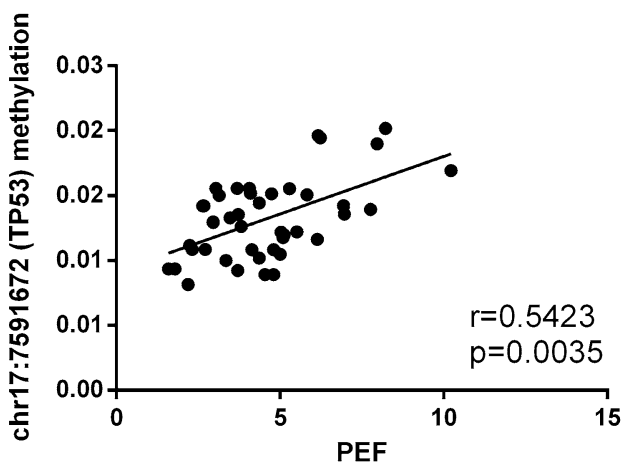

b $\div$
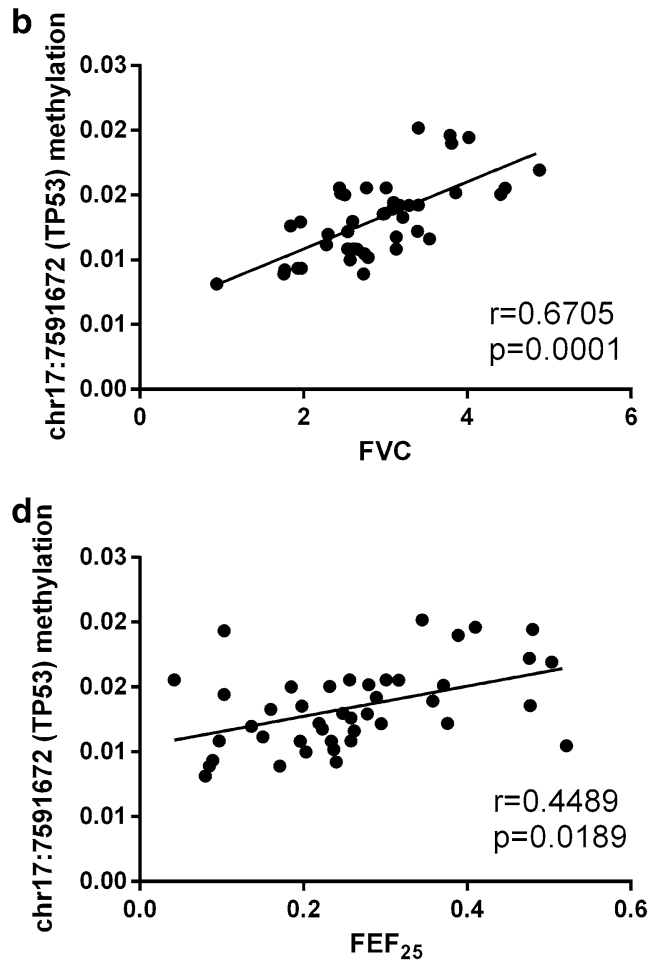

Fig. 5 Correlation analysis between chr17:7591672 (TP53) and clinical lung function. a-d The methylation level of chr17:7591672 (TP53) was positively correlated with $\mathrm{FEV}_{1}, \mathrm{FVC}, \mathrm{PEF}$ and $\mathrm{FEF}_{25}$
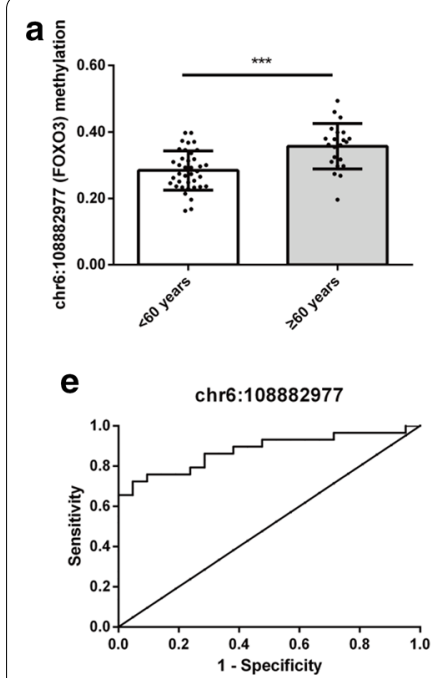

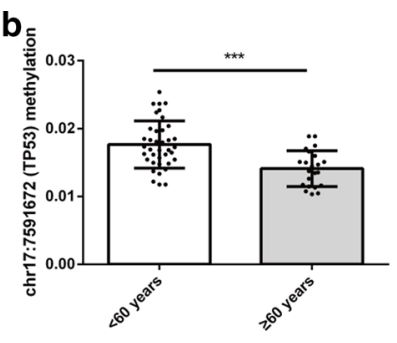

f

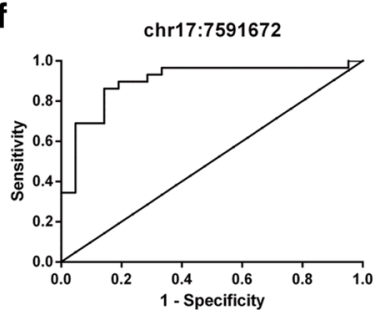

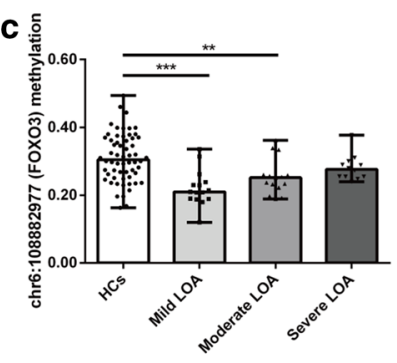

g

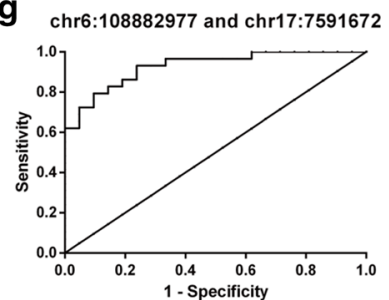

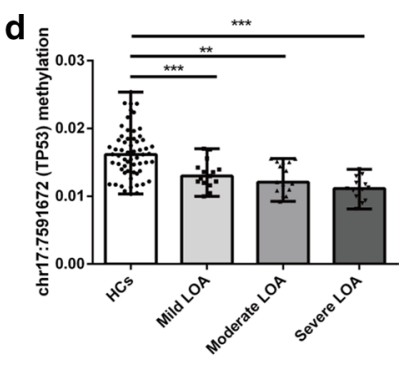

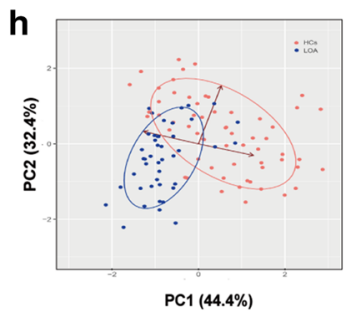

Fig. 6 DNA methylation levels of chr6:108882977 (FOXO3) and chr17:7591672 (TP53) and their accuracy in predicting LOA. a, b The methylation levels of chr6:108882977 (FOXO3) and chr17:7591672 (TP53) in the peripheral blood of HCs $<60$ years old and $\geq 60$ years old. c, d The methylation levels of chr6:108882977 (FOXO3) and chr17:7591672 (TP53) in peripheral blood of LOA patients and HCs. e ROC curve of DMS (chr6:108882977) and age. $\mathbf{f}$ ROC curve of DMS (chr17:7591672) and age. $\mathbf{g}$ ROC curve of the two DMSs and age. (H) A PCA plot consisting of the two DMSs and age. ${ }^{*} p<0.05 ;{ }^{* *} p<0.01 ;{ }^{* *} p<0.001$ 


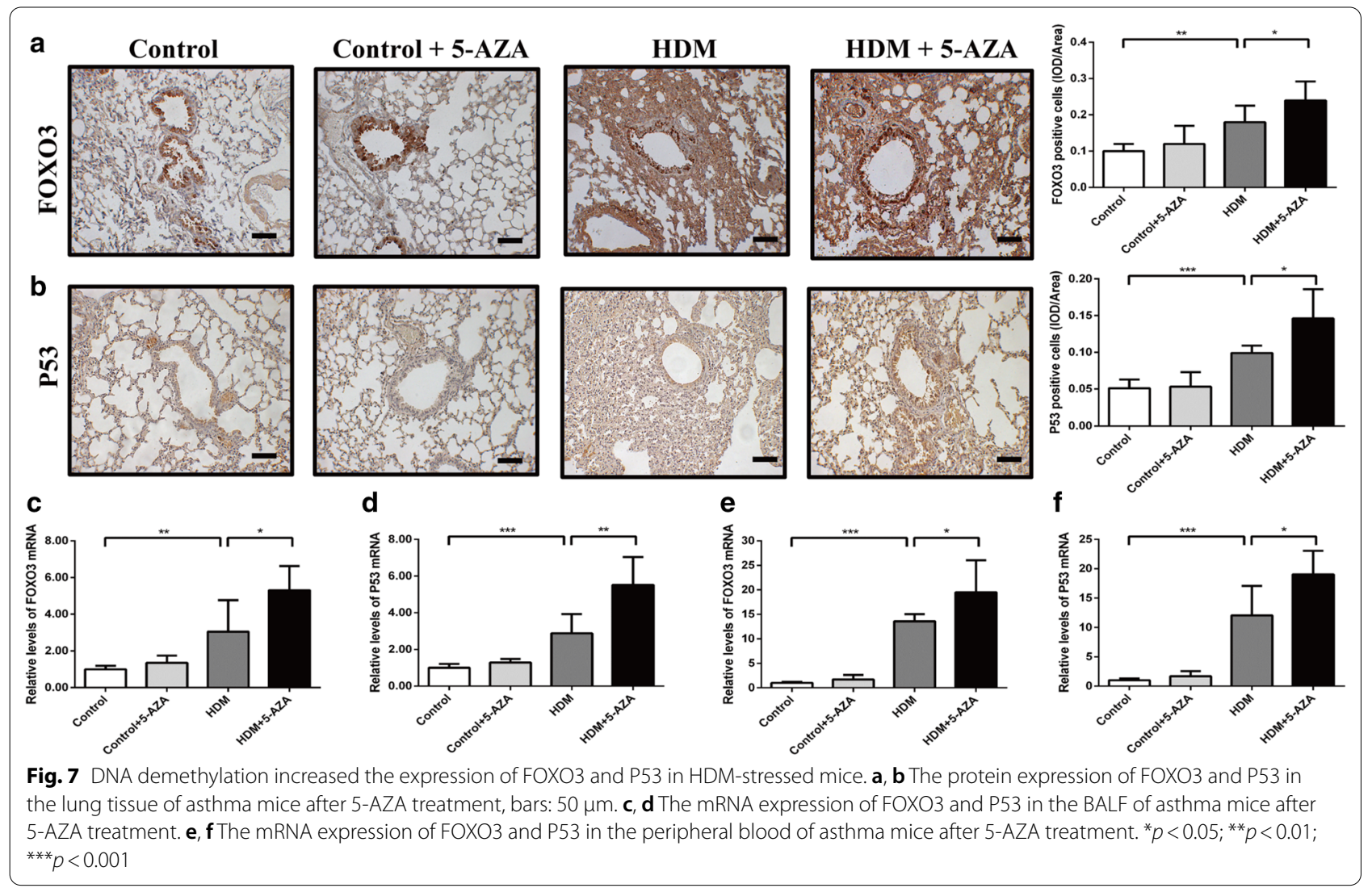

levels of chr6:108882977. Severe asthma had complex pathological mechanisms and substantial differences in cytokine production compared to mild and moderate asthma, particularly in Th1 and Th17 cells. And the cytokine expression patterns of these cells triggered interactions among pathways [65]. Thus, we speculated that cytokine pathway interactions in severe LOA may affect FOXO3 expression, not just DNA methylation, which still needs further research to verify. Most notably, the ROC curve analysis and PCA suggested that the DNA methylation levels of chr6:108882977 and chr17:7591672 in the peripheral blood can effectively distinguish LOA patients from HCs. This correlation strongly suggests that the methylation level of the chr6:108882977 in FOXO3 and chr17:7591672 in TP53 can be used as a blood biomarker to predict and screen LOA. This DNA methylation detection from peripheral blood is convenient and cost-effective, which is an ideal choice to be the novel biomarkers of LOA.

Although these specific CpG sites may provide blood biomarker to predict and screen LOA, there are still some limitations in this study. The first one is the relatively limited sample size, a new LOA cohort or Long-standing asthma cohort (Age of onset $<12$ years) should be collected in our further work. Besides, the regulation of the specific CpG site methylation on the expression of FOXO3 and TP53 still needs further verification. Moreover it have been verified that FOXO3 and TP53 are expressed in eosinophils and neutrophils [66-69]. Further studies are needed to explore the cellular and molecular mechanisms by which DNA methylation regulated the expression of FOXO3 and TP53.

\section{Conclusions}

In summary, this study verified the altered mRNA expression of FOXO3 and TP53 in the peripheral blood of LOA patients, which may be due to the regulation of DNA methylation. Besides, the DNA methylation levels of the chr6:108882977 in FOXO3 and chr17:7591672 in TP53 in peripheral blood were associated with the clinically phenotypic which may be used as effective blood biomarkers of LOA. These results provide some useful insights into the molecular mechanisms of aging-related genes in LOA which provide some potential useful targets for early prediction and screening of LOA. 


\begin{abstract}
Abbreviations
Forkhead Box O3: FOXO3; DMSs: Differentially methylated sites; ROC: Receiver operating characteristic; PCA: Principal components analysis; 5-AZA 5-Aza-2'-deoxycytidine; COPD: Chronic obstructive pulmonary disease; FEV Forced expiratory volume in one second; FEV $1 \%$ : Forced expiratory volume in one second as percentage of predicted volume; FVC: Forced vital capacity; PEF: Peak expiratory flow; FEF: Forced expiratory flow.
\end{abstract}

\section{Supplementary Information}

The online version contains supplementary material available at https://doi. org/10.1186/s12967-020-02643-y.

\section{Additional file 1: Table S1. Details of $\mathrm{CpG}$ regions in the $\mathrm{CpG}$ islands of} FOXO3 and TP53.

Additional file 2: Table S2. Methylation level of each CpG site in the CpG islands of FOXO3 and TP53.

Additional file 3: Table S3. Correlation between mRNA expression of FOXO3 and TP53 and clinical parameters in LOA patients.

Additional file 4: Table S4. Correlation between DNA methylation levels and clinical parameters in LOA patients.

Additional file 5: Figure S1. The sensitivity and specificity of 6 DMSs in predicting LOA.

\section{Acknowledgements}

We appreciate the Key laboratory of Basic and Clinical Respiratory Diseases in Hunan Province for offering the equipment and experiment condition.

\section{Authors' contributions}

$Y L$ : carried out the experiments, analyzed and interpreted the data and drafted the manuscript. YL, WM and YY, YM: collected clinical samples. WL, DX, QL, $Z Z$ and ZK: performed the experiments and statistical analysis. XY, QX, LH, QX and LC: analyzed and interpreted the data, provided the project funding and revised the manuscript. LC: analyzed and interpreted the data, revised the manuscript and finally approved the version of the manuscript for publication. All authors provided critical feedback and helped shape the research, analysis and manuscript. All authors read and approved the final manuscript.

\section{Funding}

This work was funded by Grants \#82070034, \#81970033, \#31900424, \#81670002 and \#31671188 from the NSFC; grants \#2020JJ4776, \#2020JJ4688, \#2019JJ50760 from the Hunan Natural Science Foundation; grant \#20K142 from open Foundation of Hunan College Innovation Program and grants \#2019zzts327, \#2019zzts1008 from the Fundamental Research Funds for the Central Universities of Central South University.

\section{Availability of data and materials}

Not applicable.

\section{Ethics approval and consent to participate}

This study was approved by Document No. 20180308 of the Xiangya Hospital Ethics Review Committee. All necessary informed consents in writing were obtained from all patients for permission to use their clinical information and samples for analysis.

\section{Consent for publication}

Not applicable.

\section{Competing interests}

The authors declare that they have no competing interests.

\section{Author details}

${ }^{1}$ Department of Respiratory Medicine, National Clinical Research Center for Respiratory Diseases, Xiangya Hospital, Central South University, Changsha, Hunan, China. ${ }^{2}$ Department of Physiology, Xiangya School of Basic Medicine Science, Central South University, Changsha 410078, Hunan, China. ${ }^{3}$ Basic and Clinical Research Laboratory of Major Respiratory Diseases, Central South
University, Changsha, Hunan, China. ${ }^{4}$ Centre for Asthma and Respiratory Disease, School of Biomedical Sciences and Pharmacy, Faculty of Health and Medicine, University of Newcastle and Hunter Medical Research Institute, Callaghan, NSW, Australia. ${ }^{5}$ Research Center of China-Africa Infectious Diseases, Xiangya School of Medicine, Central South University, Changsha, Hunan, China.

Received: 4 June 2020 Accepted: 27 November 2020

Published online: 09 December 2020

\section{References}

1. Lau MY, Dharmage SC, Burgess JA, Win AK, Lowe AJ, Lodge C, Perret J, Hui J, Thomas PS, Morrison S, et al. The interaction between farming/rural environment and TLR2, TLR4, TLR6 and CD14 genetic polymorphisms in relation to early- and late-onset asthma. Sci Rep. 2017;7:43681.

2. Hirano T, Matsunaga K. Late-onset asthma: current perspectives. J Asthma Allergy. 2018;11:19-27.

3. Skloot GS. The effects of aging on lung structure and function. Clin Geriatr Med. 2017;33:447.

4. Vitenberga Z, Pilmane M. Age-related lung tissue remodeling due to the local distribution of MMP-2, TIMP-2, TGF-beta and Hsp70. Biotech Histochem. 2018:93:239-48.

5. Hamsanathan S, Alder JK, Sellares J, Rojas M, Gurkar AU, Mora AL. Cellular senescence: the Trojan horse in chronic lung diseases. Am J Respir Cell Mol Biol. 2019;61:21-30.

6. Fragoso CA. Epidemiology of chronic obstructive pulmonary disease (COPD) in aging populations. COPD. 2016;13:125-9.

7. Brandsma CA, de Vries M, Costa R, Woldhuis RR, Konigshoff M, Timens $W$. Lung ageing and COPD: is there a role for ageing in abnormal tissue repair? Eur Respir Rev. 2017;26:170073.

8. Dunn RM, Busse PJ, Wechsler ME. Asthma in the elderly and late-onset adult asthma. Allergy. 2018;73:284-94.

9. Feng $Z$, Lin M, Wu R. The regulation of aging and longevity: a new and complex role of p53. Genes Cancer. 2011;2:443-52.

10. Kahn AJ. FOXO3 and related transcription factors in development, aging, and exceptional longevity. J Gerontol Ser A Biol Sci Med Sci. 2015;70:421-5.

11. Kaestner $\mathrm{KH}$, Knochel W, Martinez DE. Unified nomenclature for the winged helix/forkhead transcription factors. Genes Dev. 2000;14:142-6.

12. Wilicox BJ, Donlon TA, He Q, Chen R, Grove JS, Yano K, Masaki KH, Willcox DC, Rodriguez B, Curb JD. FOXO3A genotype is strongly associated with human longevity. Proc Natl Acad Sci USA. 2008;105:13987-92.

13. Soerensen M, Dato S, Christensen K, McGue M, Stevnsner T, Bohr VA, Christiansen L. Replication of an association of variation in the FOXO3A gene with human longevity using both case-control and longitudinal data. Aging Cell. 2010;9:1010-7.

14. Hwang JW, Rajendrasozhan S, Yao H, Chung S, Sundar IK, Huyck HL, Pryhuber GS, Kinnula VL, Rahman I. FOXO3 deficiency leads to increased susceptibility to cigarette smoke-induced inflammation, airspace enlargement, and chronic obstructive pulmonary disease. J Immunol. 2011:187:987-98.

15. Ito K, Barnes PJ. COPD as a disease of accelerated lung aging. Chest 2009:135:173-80.

16. Gogebakan B, Bayraktar R, Ulasli M, Oztuzcu S, Tasdemir D, Bayram H. The role of bronchial epithelial cell apoptosis in the pathogenesis of COPD. Mol Biol Rep. 2014;41:5321-7.

17. Gu C, Li Y, Liu J, Ying X, Liu Y, Yan J, Chen C, Zhou H, Cao L, Ma Y. LncRNAmediated SIRT1/FoxO3a and SIRT1/p53 signaling pathways regulate type II alveolar epithelial cell senescence in patients with chronic obstructive pulmonary disease. Mol Med Rep. 2017;15:3129-34.

18. Saccucci P, Verrotti A, Giannini C, Verini M, Chiarelli F, Neri A, Magrini A. p53 Codon 72 genetic polymorphism in asthmatic children: evidence of interaction with acid phosphatase locus 1. Allergy Asthma Immunol Res. 2014;6:252-6.

19. Barkund S, Shah T, Ambatkar N, Gadgil M, Joshi K. FOXO3a gene polymorphism associated with asthma in Indian population. Mol Biol Int. 2015;2015:638515. 
20. El Rifai NM, Al-Wakeel H, Osman HM, El Taweel RH. FOXO3a gene polymorphism and bronchial asthma in Egyptian children. Egypt J Pediatr Allergy Immunol. 2019;17:31-6.

21. Rogers LK, Cismowski MJ. Oxidative stress in the lung - the essential paradox. Curr Opin Toxicol. 2018;7:37-43.

22. Fraga MF, Esteller M. Epigenetics and aging: the targets and the marks. Trends Genet. 2007;23:413-8.

23. Skvortsova K, lovino N, Bogdanovic O. Functions and mechanisms of epigenetic inheritance in animals. Nat Rev Mol Cell Biol. 2018;19:774-90

24. Liang $Y$, Wang $P$, Zhao $M$, Liang G, Yin H, Zhang G, Wen H, Lu Q. Demethylation of the FCER1G promoter leads to FcepsilonRI overexpression on monocytes of patients with atopic dermatitis. Allergy. 2012;67:424-30.

25. Busch R, Qiu WL, Lasky-Su J, Morrow J, Criner G, DeMeo D. Differential DNA methylation marks and gene comethylation of COPD in AfricanAmericans with COPD exacerbations. Respiratory Research. 2016;17:143.

26. Kundakovic M, Gudsnuk K, Herbstman JB, Tang DL, Perera FP, Champagne FA. DNA methylation of BDNF as a biomarker of early-life adversity. Proc Natl Acad Sci USA. 2015;112:6807-13.

27. Sun B, Hu L, Luo ZY, Chen XP, Zhou HH, Zhang W. DNA methylation perspectives in the pathogenesis of autoimmune diseases. Clin Immunol. 2016;164:21-7.

28. Hulbert A, Jusue-Torres I, Stark A, Chen C, Rodgers K, Lee B, Griffin C, Yang A, Huang P, Wrangle J, et al. Early detection of lung cancer using DNA promoter hypermethylation in plasma and sputum. Clin Cancer Res. 2017;23:1998-2005.

29. Woodson K, Mason J, Choi SW, Hartman T, Tangrea J, Virtamo J, Taylor PR, Albanes D. Hypomethylation of p53 in peripheral blood DNA is associated with the development of lung cancer. Cancer Epidemiol Biomark Prev. 2001;10:69-74.

30. Gong C, Yao S, Gomes AR, Man EPS, Lee HJ, Gong G, Chang S, Kim SB, Fujino K, Kim SW, et al. BRCA1 positively regulates $\mathrm{FOXO} 3$ expression by restricting $\mathrm{FOXO} 3$ gene methylation and epigenetic silencing through targeting EZH2 in breast cancer. Oncogenesis. 2016;5:e214.

31. Bateman ED, Hurd SS, Barnes PJ, Bousquet J, Drazen JM, FitzGerald JM, Gibson P, Ohta K, O'Byrne P, Pedersen SE, Pizzichini E, Sullivan SD, Wenzel $\mathrm{SE}$, Zar HJ. Global strategy for asthma management and prevention: GINA executive summary. Eur Respir J. 2008;31:143-78.

32. Kaur R, Chupp G. Phenotypes and endotypes of adult asthma: moving toward precision medicine. J Allergy Clin Immunol. 2019;144:1-12.

33. Song WJ, Sintobin I, Sohn KH, Kang MG, Park HK, Jo EJ, Lee SE, Yang MS, Kim SH, Park HK, et al. Staphylococcal enterotoxin IgE sensitization in late-onset severe eosinophilic asthma in the elderly. Clin Exp Allergy. 2016;46:411-21.

34. Ulrik CS. Late-onset asthma: a diagnostic and management challenge. Drugs Aging. 2017;34:157-62

35. Pizzichini E, Pizzichini MM, Efthimiadis A, Evans S, Morris MM, Squillace D, Gleich GJ, Dolovich J, Hargreave FE. Indices of airway inflammation in induced sputum: reproducibility and validity of cell and fluid-phase measurements. Am J Respir Crit Care Med. 1996;154:308-17.

36. Liu C, Yuan L, Zou Y, Yang M, Chen Y, Qu X, Liu H, Jiang J, Xiang Y, Qin X. ITGB4 is essential for containing HDM-induced airway inflammation and airway hyperresponsiveness. J Leukoc Biol. 2018;103:897-908.

37. Liu C, Qin X, Liu H, Xiang Y. Downregulation of integrin beta4 decreases the ability of airway epithelial cells to present antigens. PLOS ONE. 2012;7:e32060.

38. Ngalamika O, Liang G, Zhao M, Yu X, Yang Y, Yin H, Liu Y, Yung S, Chan TM, Lu Q. Peripheral whole blood FOXP3 TSDR methylation: a potential marker in severity assessment of autoimmune diseases and chronic infections. Immunol Invest. 2015;44:126-36.

39. Li JJ, Li S, Zhu CG, Wu NQ, Zhang Y, Guo YL, Gao Y, Li XL, Qing P, Cui CJ, et al. Familial hypercholesterolemia phenotype in chinese patients undergoing coronary angiography. Arterioscler Thromb Vasc Biol. 2017:37:570-9.

40. Du XZ, Yuan L, Wu MP, Men MC, He RX, Wang LY, Wu SY, Xiang Y, Qu XP, Liu $\mathrm{HJ}$, et al. Variable DNA methylation of aging-related genes is associated with male COPD. Respir Res. 2019:20:243.

41. Wu M, Yang Y, Yuan L, Yang M, Wang L, Du X, Qin L, Wu S, Xiang Y, Qu $X$, et al. DNA methylation down-regulates integrin beta4 expression in asthmatic airway epithelial cells. Clin Exp Allergy. 2020. https://doi.org/10. 1111/cea.13697.
42. Guo C, Pei L, Xiao X, Wei Q, Chen JK, Ding HF, Huang S, Fan G, Shi H, Dong Z. DNA methylation protects against cisplatin-induced kidney injury by regulating specific genes, including interferon regulatory factor 8 . Kidney Int. 2017:92:1194-205.

43. Miravitlles M, Guerrero T, Mayordomo C, Sanchez-Agudo L, Nicolau F, Segu JL. Factors associated with increased risk of exacerbation and hospital admission in a cohort of ambulatory COPD patients: a multiple logistic regression analysis. The EOLO Study Group. Respiration. 2000;67:495-501.

44. Brenet F, Moh M, Funk P, Feierstein E, Viale AJ, Socci ND, Scandura JM. DNA methylation of the first exon is tightly linked to transcriptional silencing. Plos ONE. 2011;6:e14524.

45. Hanania NA, King MJ, Braman SS, Saltoun C, Wise RA, Enright P, Falsey AR, Mathur SK, Ramsdell JW, Rogers L, et al. Asthma in the elderly: current understanding and future research needs - a report of a National Institute on Aging (NIA) workshop. J Allergy Clin Immunol. 2011;128:S4-24.

46. Tsai CL, Lee WY, Hanania NA, Camargo CA Jr. Age-related differences in clinical outcomes for acute asthma in the United States, 2006-2008. J Allergy Clin Immunol. 2012;129(1252-1258):e1251.

47. Konecny M, Markus J, Waczulikova I, Dolesova L, Kozlova R, Repiska V, Novosadova H, Majer I. The value of SHOX2 methylation test in peripheral blood samples used for the differential diagnosis of lung cancer and other lung disorders. Neoplasma. 2016;63:246-53.

48. Unnikrishnan A, Freeman WM, Jackson J, Wren JD, Porter H, Richardson A. The role of DNA methylation in epigenetics of aging. Pharmacol Ther. 2019;195:172-85.

49. Myatt SS, Lam EW. The emerging roles of forkhead box (Fox) proteins in cancer. Nat Rev Cancer. 2007;7:847-59.

50. Amarin JZ, Naffa RG, Suradi HH, Alsaket YM, Obeidat NM, Mahafza TM, Zihlif MA. An intronic single-nucleotide polymorphism (rs13217795) in FOXO3 is associated with asthma and allergic rhinitis: a case-case-control study. BMC Med Genet. 2017:18:132.

51. Tsai MJ, Tsai YC, Chang WA, Lin YS, Tsai PH, Sheu CC, Kuo PL, Hsu YL. Deducting microRNA-mediated changes common in bronchial epithelial cells of asthma and chronic obstructive pulmonary disease-a nextgeneration sequencing-guided bioinformatic approach. Int J Mol Sci. 2019;20:553.

52. Miller RL, Ho SM. Environmental epigenetics and asthma_current concepts and call for studies. Am J Respir Crit Care Med. 2008;177:567-73.

53. Ferrari $L$, Carugno M, Bollati V. Particulate matter exposure shapes DNA methylation through the lifespan. Clin Epigenet. 2019. https://doi.org/10. 1186/s13148-019-0726- $x$.

54. Sanese P, Forte G, Disciglio V, Grossi V, Simone C. FOXO3 on the road to longevity: lessons from SNPs and chromatin hubs. Comput Struct Biotechnol J. 2019;17:737-45.

55. Marusyk A, Wheeler L, Mathews CK, DeGregori J. p53 mediates senescence-like arrest induced by chronic replicational stress. Mol Cell Biol. 2007:27:5336-51.

56. Abbas T, Dutta A. p21 in cancer: intricate networks and multiple activities. Nat Rev Cancer. 2009;9:400-14.

57. Wu CH, Lin HH, Yan FP, Wu CH, Wang CJ. Immunohistochemical detection of apoptotic proteins, p53/Bax and JNK/FasL cascade, in the lung of rats exposed to cigarette smoke. Arch Toxicol. 2006;80:328-36.

58. Cardenas A, Sordillo JE, Rifas-Shiman SL, Chung W, Liang L, Coull BA, Hivert MF, Lai PS, Forno E, Celedon JC, et al. The nasal methylome as a biomarker of asthma and airway inflammation in children. Nat Commun. 2019;10:3095

59. Pollutri D, Gramantieri L, Bolondi L, Fornari F. TP53/MicroRNA interplay in hepatocellular carcinoma. Int J Mol Sci. 2016;17:2029.

60. Wang XF, Wang L, Mo QJ, Jia AK, Dong YQ, Wang GQ. A positive feedback loop of p53/miR-19/TP53INP1 modulates pancreatic cancer cell proliferation and apoptosis. Oncol Rep. 2016;35:518-23.

61. Lutzner N, Kalbacher H, Krones-Herzig A, Rosl F. FOXO3 is a glucocorticoid receptor target and regulates LKB1 and its own expression based on cellular AMP levels via a positive autoregulatory loop. Plos One. 2012;7:e42166

62. An YF, Wang B, Wang X, Dong GY, Jia JH, Yang Q. SIRT1 inhibits chemoresistance and cancer stemness of gastric cancer by initiating an AMPK FOXO3 positive feedback loop. Cell Death Dis. 2020. https://doi.org/10. 1038/s41419-020-2308-4. 
63. Jones PA, Takai D. The role of DNA methylation in mammalian epigenetics. Science. 2001;293:1068-70.

64. Ehrlich M. Expression of various genes is controlled by DNA methylation during mammalian development. J Cell Biochem. 2003;88:899-910.

65. Poon AH, Eidelman DH, Martin JG, Laprise C, Hamid Q. Pathogenesis of severe asthma. Clin Exp Allergy. 2012;42:625-37.

66. Hu X, Wang J, Xia Y, Simayi M, Ikramullah S, He Y, Cui S, Li S, Wushouer Q Resveratrol induces cell cycle arrest and apoptosis in human eosinophils from asthmatic individuals. Mol Med Rep. 2016:14:5231-6.

67. Rosas M, Dijkers PF, Lindemans CL, Lammers JJ, Koenderman L, Coffer PJ. IL-5-mediated eosinophil survival requires inhibition of GSK-3 and correlates with beta-catenin relocalization. J Leukoc Biol. 2006;80:186-95.

68. Majewska E, Sulowska Z, Baj Z. Spontaneous apoptosis of neutrophils in whole blood and its relation to apoptosis gene proteins. Scand J Immunol. 2000;52:496-501
69. Turrel-Davin F, Tournadre A, Pachot A, Arnaud B, Cazalis MA, Mougin B, Miossec $P$. FoxO3a involved in neutrophil and T cell survival is overexpressed in rheumatoid blood and synovial tissue. Ann Rheum Dis. 2010;69:755-60.

\section{Publisher's Note}

Springer Nature remains neutral with regard to jurisdictional claims in published maps and institutional affiliations.
Ready to submit your research? Choose BMC and benefit from:

- fast, convenient online submission

- thorough peer review by experienced researchers in your field

- rapid publication on acceptance

- support for research data, including large and complex data types

- gold Open Access which fosters wider collaboration and increased citations

- maximum visibility for your research: over $100 \mathrm{M}$ website views per year

At BMC, research is always in progress.

Learn more biomedcentral.com/submissions 